\title{
Transcriptional profiling of human bronchial epithelial cell BEAS-2B exposed to diesel and biomass ultrafine particles
}

\author{
Andrea Grilli ${ }^{1,2}$, Rossella Bengallii ${ }^{3 \dagger}$, Eleonora Longhin ${ }^{3 \dagger}$, Laura Capasso $^{3}$, Maria Carla Proverbio ${ }^{4}$, Mattia Forcato ${ }^{1}$, \\ Silvio Bicciato ${ }^{1}$, Maurizio Gualtieri ${ }^{5,6}$, Cristina Battaglia ${ }^{7,8^{*}}$ (D) and Marina Camatini ${ }^{3}$
}

\begin{abstract}
Background: Emissions from diesel vehicles and biomass burning are the principal sources of primary ultrafine particles (UFP). The exposure to UFP has been associated to cardiovascular and pulmonary diseases, including lung cancer. Although many aspects of the toxicology of ambient particulate matter (PM) have been unraveled, the molecular mechanisms activated in human cells by the exposure to UFP are still poorly understood. Here, we present an RNA-seq time-course experiment (five time point after single dose exposure) used to investigate the differential and temporal changes induced in the gene expression of human bronchial epithelial cells (BEAS-2B) by the exposure to UFP generated from diesel and biomass combustion. A combination of different bioinformatics tools (EdgeR, next-maSigPro and reactome FI app-Cytoscape and prioritization strategies) facilitated the analyses the temporal transcriptional pattern, functional gene set enrichment and gene networks related to cellular response to UFP particles.

Results: The bioinformatics analysis of transcriptional data reveals that the two different UFP induce, since the earliest time points, different transcriptional dynamics resulting in the activation of specific genes. The functional enrichment of differentially expressed genes indicates that the exposure to diesel UFP induces the activation of genes involved in TNFa signaling via NF-kB and inflammatory response, and hypoxia. Conversely, the exposure to ultrafine particles from biomass determines less distinct modifications of the gene expression profiles. Diesel UFP exposure induces the secretion of biomarkers associated to inflammation (CCXL2, EPGN, GREM1, IL1A, IL1B, IL6, IL24, EREG, VEGF) and transcription factors (as NFE2L2, MAFF, HES1, FOSL1, TGIF1) relevant for cardiovascular and lung disease. By means of network reconstruction, four genes (STAT3, HIF1a, NFKB1, KRAS) have emerged as major regulators of transcriptional response of bronchial epithelial cells exposed to diesel exhaust.
\end{abstract}

Conclusions: Overall, this work highlights modifications of the transcriptional landscape in human bronchial cells exposed to UFP and sheds new lights on possible mechanisms by means of which UFP acts as a carcinogen and harmful factor for human health.

Keywords: Ultrafine particles, Biomass particles, Diesel particles, Lung disorders, BEAS-2B, RNA-seq, Time-course, Gene network, Environmental particles, Human health

\footnotetext{
*Correspondence: cristina.battaglia@unimi.it

${ }^{\dagger}$ Equal contributors

${ }^{7}$ Department of Medical Biotechnology and Translational Medicine

(BIOMETRA), University of Milan, Via Fratelli Cervi 93, 20090 Segrate, Italy

${ }^{8}$ Institute for Biomedical Technologies, National Research Council (ITB-CNR),

Via Fratelli Cervi 93, 20090 Segrate, Italy

Full list of author information is available at the end of the article
}

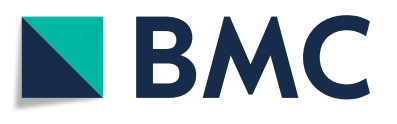

(c) The Author(s). 2018 Open Access This article is distributed under the terms of the Creative Commons Attribution 4.0 International License (http://creativecommons.org/licenses/by/4.0/), which permits unrestricted use, distribution, and reproduction in any medium, provided you give appropriate credit to the original author(s) and the source, provide a link to the Creative Commons license, and indicate if changes were made. The Creative Commons Public Domain Dedication waiver (http://creativecommons.org/publicdomain/zero/1.0/) applies to the data made available in this article, unless otherwise stated. 


\section{Background}

Combustion processes are the principal sources of primary ultrafine particles (UFP) and emissions from diesel vehicles and biomass burning account for the majority of ambient UFP [1]. Exposure to these particles have been linked to cardiovascular and pulmonary diseases, including lung cancer $[2,3]$. Epidemiological and clinical evidences exist for both acute and chronic effects of combustion particles. Long-term epidemiologic studies have reported an increased risk of mortality from cardiopulmonary symptoms and lung cancer [2]. Acute exposure to traffic particulate matter (PM) has been directly linked to triggering of myocardial infarction [3] and studies involving volunteers exposed to UFP highlighted a higher rate of adverse vascular effects $[4,5]$.

The mechanisms of PM and UFP toxicity are multiple and greatly depend on the different combustion conditions under which particles are generated and, ultimately, on their chemical composition [5]. Several in vitro and in vivo studies unraveled diverse aspects of PM toxicology. Biomass and diesel combustions emit primary nanoparticles and are among the most important contributors to the total emitted UFP [6]. While diesel particles have been largely investigated, less data are available for particles derived from biomass combustion. Recently, we investigated the physicochemical properties and associated cellular effects of diesel and biomass UFP produced under controlled laboratory conditions [7]. Here, we report the analysis of the transcriptional changes induced in human bronchial cells by the exposure to UFP produced by the diesel and biomass combustion.

Oxidative stress and inflammation are the main cellular responses driving the effects of air borne PM and combustion-derived [3, 8]. UFP from diesel exhaust and biomass burning are enriched in organic compounds, such as polycyclic aromatic hydrocarbons (PAHs) and their derived molecules, that bind to and activate the aryl hydrocarbon receptor (AhR) [9]. AhR is responsible for the transcription of genes involved in responses to DNA damage and in xenobiotic metabolism. Although other mechanisms may concur, the metabolism and consequent activation of PAHs by the xenobiotic pathway is considered the main mechanism of diesel-induced reactive oxygen species (ROS) generation and oxidative stress [1]. AhR has also been reported to directly participate in the activation of the inflammatory response by diesel and traffic-related PM [10, 11]. In addition, oxidative stress itself is considered a main mechanism of dieselinduced inflammation, as ROS formation may activate redox-sensitive transcription factors involved in the regulation of pro-inflammatory genes, such as $N F-\kappa B$ and Nrf2 [8]. In mice, cardiovascular effects derived from the exposure to ambient and diesel PM have been related to airway inflammation and to the release of inflammation cytokines such as TNF- $\alpha$ and IL-6 [1214]. Overall, these mechanisms might contribute to carcinogenesis, the complex process leading to tumor formation. DNA oxidative damage by ROS and DNA adducts formation by electrophilic reactive products of PAHs are known to be implicated in the initiation stage of carcinogenesis [2]. Both inflammation and oxidative stress can contribute to the promotion and progression of carcinogenesis by altering the expression of genes related to cell differentiation, growth, proliferation and migration. Inflammatory events also contribute to the modification of the tumor microenvironment, enhancing angiogenesis and suppressing the immune system $[2,15]$.

Although genome-wide approaches have been previously used to assess the effect of PM on health [16], the impact of UFP exposure on gene expression remains under-investigated leaving largely undefined the effect of UFP on the transcriptional dynamics in human cells. To elucidate how UFP from diesel vehicles and biomass burning emissions modulate gene expression dynamics in bronchial epithelial cells, we performed a time course RNA-seq experiment in BEAS-2B cells, after exposure to a single dose of these emissions. The design of time course experiment allowed identification of early transcriptional events, likely involved in the activation of pivotal signaling cascades, and of hallmark processes linking UFP exposure to molecular mechanism underlying human diseases.

\section{Methods}

\section{Particle sample collection}

Diesel particles were sampled from a Euro IV light duty vehicle without diesel particle filter (DPF), fuelled by commercial diesel and run over a chassis dyno. A "URBAN" Artemis Driving Cycle was used to represent the average "stop \& go" driving conditions typical of a European city urban context. To collect the particles mass necessary for biological and chemical analyses, we performed 30 driving cycles. In particular, 5 cycles were performed at the beginning of the experimentation to set up the sampling condition and 5 at the end of the sampling campaign to confirm that the performances of the vehicle were not modified. The remaining 20 cycles were used to collect particles for the biological analysis and chemical characterization. To remove aggregates larger than $1 \mu \mathrm{m}$, particles were collected on Teflon filters (Whatman), using a DGI-1570 (Dekati Gravimetric Impactor, Finland). Biomass particles were produced by a modern automatic $25 \mathrm{~kW}$ boiler, propelled with prime quality spruce pellet. To improve volatile organic compounds condensation, particles were sampled on Teflon filters after dilution of flue gases with clean air. Filters were kept at $-20{ }^{\circ} \mathrm{C}$ immediately after sampling, until chemical characterization or UFP extraction for 
biological tests was performed. A chemical and morphological characterization of particles has been conducted as in [7]; briefly, transmission electron microscopy (TEM) analysis of both diesel and biomass samples showed aggregates of soot particles, with dimension lower than $50 \mathrm{~nm}$. Chemical characterization showed that metal content was higher in diesel samples, with the exception of $\mathrm{Mn}$ and $\mathrm{K}$ that were higher in biomass. Diesel particles were characterized by the presence of transition metals such as $\mathrm{Fe}, \mathrm{Zn}, \mathrm{Cr}, \mathrm{Pb}, \mathrm{V}$ and Ni. Speciation showed a typical composition of PAHs associated with diesel soot with high levels of pyrene, phenanthrene, benzo[a]anthracene and dibenzo[a,h]anthracene, while the most abundant PAHs in biomass samples were fluoranthene and pyrene. The content of PAHs was higher in diesel (592 $\mathrm{ng} / \mathrm{mg}$ ) samples compared to biomass (55 ng/mg) ones. UFP exposed to cells were extracted from Teflon filters as described in [17]. Briefly, filters of the same source were pooled in a glass vial, covered with cold sterile water, and sonicated in an icecold water-bath (SONICA Soltec). Particle suspensions (Additional file 1: Figure S1) were dried into a desiccator weighed, and stored at $-20{ }^{\circ} \mathrm{C}$ until use. Particles were re-suspended in sterile water at a final concentration of $2 \mu \mathrm{g} / \mu \mathrm{l}$ just before use.

\section{Cell culture and experimental design of UFP exposure}

Human bronchial epithelial cells BEAS-2B were maintained in LHC-9 medium at $37{ }^{\circ} \mathrm{C}$ and $5 \%$ of $\mathrm{CO}_{2}$. Cells for treatments were seeded at a concentration of $2.7 \times$ $10^{5}$ cells/well in Cell BIND 6-well plates (Corning), and treated the day after with diesel or biomass UFP. Cell viability was assessed after $20 \mathrm{~h}$ of exposure to $2.5,5$, or $10 \mu \mathrm{g} / \mathrm{cm}^{2}$ (equivalent to 25,50 , and $100 \mu \mathrm{g} / \mathrm{ml}$ ) of UFP by Alamar Blue assay accordingly to manufacturer's instructions (Life technologies). Cells were sampled at 1 , $4,8,16$, and $20 \mathrm{~h}$ after a single exposure to $2.5 \mu \mathrm{g} / \mathrm{cm}^{2}$ $(25 \mu \mathrm{g} / \mathrm{ml})$ of UFP and compared to untreated controls at the same time of exposure.

\section{RNA extraction and RNA sequencing}

BEAS-2B cells exposed to $2.5 \mu \mathrm{g} / \mathrm{cm}^{2}$ of UFP or medium alone were collected at $1,4,8,16$, and $20 \mathrm{~h}$, lysed, and stored in QIAzol Lysis reagent (Qiagen, Hilden, Germany) until RNA extraction. Three independent biological replicates were examined at each time point in UFP exposed and paired controls samples for a total of 45 samples. Total RNA was extracted using the miRNeasy extraction kit (Qiagen, Hilden, Germany) and eluted in RNase free-water, according to the manufacturer's recommended guidelines. Quality and quantity of the total RNA samples were evaluated with 2100 Bioanalyzer (Agilent, Santa Clara, CA) and Nanodrop 1000 (Thermo Fisher Scientific, Wilmington, DE), respectively. Only RNA samples with RIN score more than 9 were considered. Same RNA samples were used either for RNA-seq and for qPCR validation. RNA-seq library was prepared from $1.5 \mu \mathrm{g}$ of total RNA using TruSeq Stranded mRNA Library Prep Kit in paired end format (Illumina) following the manufacturer's recommendations. RNA sequencing was carried out on Illumina HiSeq2500 platform (Illumina) at IGA technology service (Istituto Genomica Applicata, Udine, Italy). RNA-seq raw and processed data are deposited in the Array Express archive under the accession number EMTAB-5157.

\section{Bioinformatics analysis}

Read quality assessment and trimming were obtained by means of fastQC (version 0.11.3) and Trimmomatic (v. 0. 33) [18], respectively. First 15 bases from the start of the reads were removed by the headcrop function of Trimmomatic tool. Then, raw reads were aligned to the human genome version hg19 with TopHat [19] (version 2.1.0) changing only the mate inner distance and its S.D. to 250 and 300, respectively, respect to default parameters. Read counts for UCSC annotated genes were calculated using the htseq-count function of HTSeq tool [20] (version 0.6. 0 ) with the mode option set as union (default) for ambiguously-mapped reads.. Normalization was carried out with edgeR package [21] (version 2.12.0,) in R-3.2.2. Raw counts were normalized according to library size to obtain counts per millions (cpm) and only genes with a $\mathrm{cpm} \geq 1$ in at least three samples were retained for subsequent analyses.

Differentially expressed genes (DEGs) at each time point between treated and untreated samples were identified using a paired design with the likelihood ratio tests of the $g \operatorname{lmLRT}$ function in edgeR package and considered significant if the $p$-value was $\leq 0.05$ and the absolute Fold Change (FC) $\geq 1.2$. DEGs were annotated with the ToppGene suite (https://toppgene.cchmc.org/) [22] and prioritized by literature mining using PubMatrix [23].

Enrichment analysis was performed using the preranked tool of Gene Set Enrichment Analysis [24] (GSEA, version 2.2.1,) and the gene sets of the Molecular Signature Database Hallmarks collection (i.e., 50 gene sets representing well-defined biological processes; MSigDB http://software.broadinstitute.org/gsea/msigdb). Specifically, genes were ranked separately for each time point using the fold change value between treated and untreated samples. Gene sets smaller than 15 or larger than 500 genes were excluded; gene sets passing this filter were considered significant if the False Discovery Rate (FDR) was $\leq 0.05$ when using 1000 permutations of gene sets. To test DEGs enrichment for diseases signatures we used the ToppGene tool (https://toppgene.cchmc.org/) with the DisGeNET database (http://www.disgenet.org/), 
considering significant only the diseases with FDR corrected $p$-value $\leq 0.05$.

Groups of genes with a differential temporal expression profile in exposed cells (as compared to controls) were identified using the next-maSigPro method of the maSigPro $[25,26] \mathrm{R}$ package (version 1.34.1). Briefly, the p.vector function was used to compute a regression fit for each gene in both matrixes of cpm counts for BEAS$2 S$ exposed to diesel and biomass UFP separately. Temporally differentially expressed genes were detected using the generalized linear model $(\mathrm{glm})$ setting a pvalue $\leq 0.05$ after FDR correction. In the glm, the family parameter was set to negative.binomial to adapt the theoretical distribution of the read counts, the counts parameter was set to true, and the theta parameter which corresponds to the dispersion of the distribution_ was left to the default value of 10 , since any variation (e.g., increasing to theta $=20$ or decreasing to theta $=5$ ) induced no evident changes in the number of DEGs. Genes with significant expression changes over time were detected with a second regression model by the $t$. fit function, selecting the two.ways.backward procedure for the regression method and theta $=10$ for the negative binomial distribution. The final selection of temporally differentially expressed genes was obtained filtering the result of the second regression model with the get.siggenes function, with the $R$-squared parameter set to 0.7 and the vars parameter to groups. Finally, significant genes have been grouped into $k=9$ groups (default value) with the see.genes function, using hierarchical and two.ways.backward as clustering method and regression procedure, respectively. Genes used in the network reconstruction were selected among those satisfying at least one of the following criteria: i) a significant modulation (DEGs) in at least one time point; ii) the inclusion in at least one time point in the core enrichment of 4 manually selected significant gene sets from GSEA analysis (TNF- $\alpha$ signaling via $N F-\kappa B$; inflammatory response, epithelial mesenchymal transition(EMT); and xenobiotic metabolism); iii) a PubMatrix total score higher or equal to 15 , corresponding to at least 15 publications containing both the gene name and the terms cardiovascular diseases, lung cancer, or lung diseases. The gene network was created in Cytoscape [27] (version 3.3) using the Reactome FI plugin [28] (version 5.0). For diesel UFP, 129 genes selected using the above mentioned criteria were inputted as a list to the Reactome FI, which reconstructed gene-gene interactions using the pathway-based Reactome Functional Interaction (FI) database (version 2015). The Reactome Functional Interaction (FI) database contains both manually annotated and predicted gene-gene relationships [29]. Since genes modulation could have been induced at protein level only, we used the linker genes option to add putative linker genes in the network. Linker genes are automatically selected by the plugin algorithm among the genes that connect the higher number of genes of the input list according to the Reactome FI database annotation. Moreover, we discarded single genes, i.e. genes not linked to any node of the network $(n=7)$. Finally, fold changes have been visualized in the network using the pie chart style of the Cytoscape EnhancedGraphics plugin [30] (version 1.0.3).

\section{Validation of selected genes and proteins modulated by diesel exposure}

Expression levels of selected genes were validated by qPCR using a customized $\mathrm{RT}^{2}$ PCR profiler system (Qiagen, Hilden, Germany) and the TaqMan technology. The qPCR validations were carried out on same RNA samples used for RNA-seq analysis, comprised 4 time points $(4,8,16$, and $20 \mathrm{~h})$ and 3 biological replicates of BEAS-2B exposed to diesel UFP. The expression of each gene within each sample was normalized using the average expression levels of three housekeeping genes ( $A C T B, B 2 M, G A P D H)$. For $I L 1 B$ gene, we used a predesigned TaqMan ${ }^{\circ}$ Gene Expression assay (Hs01555410 m1) and TaqMan ${ }^{\circ}$ Universal Master Mix (Applied Biosystem, Foster City, CA) using ACTB genes (Hs99999903_ $\mathrm{m} 1)$ as reference. All qPCR reactions were processed on an Applied Biosystem 7900HT real time PCR machine. The fold change was calculated for each condition using the $2^{-\Delta \Delta C t}$ method comparing $\Delta$ Ct of UFP treated cells to $\Delta \mathrm{Ct}$ of control untreated cells.

To validate results at the protein level, the expression of four secreted proteins (i.e., IL-6, VEGF, EREG, and IL24) has been quantified with the ELISA assay (IL-6 and VEGF: Life Technologies; EREG and IL-24: Elabscience) according to the manufacturer's guidelines. The absorbance of each sample was measured using a Multiplate Reader Ascent (Thermo Fisher Scientific) at $450 \mathrm{~nm}$ and $630 \mathrm{~nm}$ and data analyzed with Ascent Software. Data are reported in $\mathrm{pg} / \mathrm{ml}$ as mean and standard error of mean (SEM) of three independent experiments. Statistical analyses were performed in Sigma Stat 3.1, using one-way ANOVA with Dunnett's or Dunn's post hoc test and $p$-value $<0.05$ for statistical significance.

\section{Results}

To investigate the effects of UFP on the gene expression dynamics, we analyzed the transcriptional profiles of BEAS-2B cells exposed for $1,4,8,16$, and $20 \mathrm{~h}$ to a single dose of $2.5 \mu \mathrm{g} / \mathrm{cm}^{2}$ (corresponding to $25 \mu \mathrm{g} / \mathrm{ml}$ ) of UFP of diesel and biomass combustion. We designed the time course in order to monitor transcriptional changes arising immediately after the exposure (e.g., $1 \mathrm{~h}$ ) and during a period that could represent a fair approximation of the exposure in a real setting (i.e., $20 \mathrm{~h}$ ). To determine the UFP dose for the time course experiment, first we assessed cell 
viability at various doses $(25,50$, and $100 \mu \mathrm{g} / \mathrm{ml})$ using the Alamar Blue assay (Additional file 2: Figure S2) and then we monitored by qPCR the transcription of few selected genes known to be involved in the cellular response to UFP exposure; finally, we selected the lowest (non-cytotoxic) dose with an effect on gene modulation (i.e., $25 \mu \mathrm{g} / \mathrm{ml}$ ). We quantified gene expression levels using RNA sequencing. The overall quality of reads from RNA-seq was good: the quality metrics only indicated the presence of a general bias in the per-base sequence content for the first 12-15 bp (the difference between $A$ and $T$, or $G$ and $C$ was greater than $20 \%$ in the first 15 bases), most likely due to an unbalanced selection of random primers. Furthermore, to elevate the mapping quality, we trimmed out the first 15 bases from all reads prior to alignment. On average, we obtained 10 million mapped reads with a mapping rate of $90.1 \%$ in the 45 analyzed samples (Additional file 3: Table S1). Starting from a total of 25,369 UCSC annotated human genes, after quantification and normalization, we retained and considered for the subsequent analyses 13,309 genes with a transcriptional signal greater than 1 count per million (cpm) in at least 3 samples (Additional file 4: Figure S3).

\section{Exposure to diesel and biomass UFP induces specific transcriptional patterns in BEAS-2B cells}

Differential expression analysis with edgeR paired design identified a variable number of differentially expressed genes (DEGs) across the five time points in samples exposed to diesel and biomass UFP as compared to unexposed controls (Fig. 1a and Additional file 5: Tables S2 and Additional file 6: Table S3). Globally, the exposure to diesel resulted in a higher number of modulated genes $(n=545)$ with respect to biomass $(n=407)$ at any time point (Fig. 1a). Interestingly, the number of DEGs induced by exposure to diesel UFP increased with time whereas the magnitude of the transcriptional modulation was variable across the time course for biomass. In general, the exposure to diesel UFP determined larger variations of the expression levels as compared to biomass. Overall, diesel and biomass induced the transcriptional modulation of 94 common genes (Additional file 7: Table S4), the majority of which (71) displayed the same pattern of expression along the time course. Among them, we found genes involved in translation (RPL27, RPL36, GSPT2, RPLP2, RPS12, RPS15A) and AhR (CYP1A1, CYP1B1, AHRR) pathways and genes encoding soluble factors involved in inflammation process and signaling (IL24, IL15, TNFSF9, NTF4, EPGN, IL1B). Few DEGs displayed a differential expression with respect to controls in more than one time point within the same treatment and only the exposure to UFP from diesel induced the statistically significant up-regulation of 11 genes along the entire time course (Fig. 1b). In particular, five of these (i.e., CYP1A1, CYP1B1, IL24, ADAMTS15, and
SHISA2) showed an almost constantly growing upregulation along the entire experiment, while six genes (EPGN, IL1A, IL1B, IGFBP1, TIPARP, and NPTX1) displayed a variable up-regulation at the different time points (Additional file 8: Figure S4). Despite some small differences in the three biological replicates, expression data of DEGs were able to clearly partition exposed cells from controls (Fig. 1c). To validate relevance of identified signatures in lung diseases, we compared DEGs to publicly available datasets. We limited the analysis to genes most constantly modulated during time, e.g. in at least 3 out of 5 time points, for a total of 53 and 3 genes for diesel and biomass, respectively. By ToppGene enrichment analysis with the DisGeNET database, we observed a significant involvement to several cancer-related disorders for DEGs induced by diesel UFP: Squamous Cell Carcinoma (FDR p-value: 4. 791E-7), Chemical Carcinogenesis (FDR p-value: 6.405E-5), Squamous cell carcinoma of the head and neck (FDR pvalue: 6.405E-5) and Lung Adenocarcinoma (FDR p-value: $8.653 \mathrm{E}-5)$ were among top significantly enriched diseases. No significant diseases were found for biomass UFPinduced DEGs because of the low number of genes.

To functionally characterize transcriptional patterns, we applied the pre-ranked gene set enrichment analysis (GSEA) to 50 hallmark gene sets, i.e., to lists of genes summarizing well-characterized biological mechanisms with coherent expression levels. GSEA highlighted that exposure to diesel and biomass UFP induced the modulation of 42 and 33 hallmark gene sets in at least 1 time point, respectively (Additional file 9: Table S5 and Additional file 10: Table S6). The more massive modulation occurred at $20 \mathrm{~h}$ with 33 gene sets significantly modulated by diesel and 20 by biomass exposure (with a $95 \%$ statistical confidence, FDR $\leq 0.05)$. TNF- $\alpha$ signaling via $N F-\kappa B$, Hypoxia and Inflammatory response gene sets resulted up-regulated by both treatments after $20 \mathrm{~h}$ of exposure (Table 1). In cells exposed to diesel UFP, the gene set of $T N F-\alpha$ signaling via $N F-k B$ was strongly and steadily enriched across the entire time course differently from other gene sets (as P53 pathway, EMT, and xenobiotic metabolism) that were mostly enriched only after $20 \mathrm{~h}$ of exposure (Fig. 2).

Interestingly, when considering genes mostly contributing to the enrichment of the TNF- $\alpha$ signaling via NF-kB gene set at the various time points, we identified 21 core enrichment genes (i.e., AREG, CDKN1A, CXCL2, EGR1, F3, FOSL1, ICOSLG, IER3, IL1A, IL1B, IRF1, LIF, MAFF, NFE2L2, PHLDA1, SERPINB2, SLC16A6, TGIF1, TIPARP, TSC22D1, VEGFA) conserved across all time points. Some of these genes code for secreted proteins (as $I L 1 A, I L 1 B$, $L I F, E R E G, C X C L 2, F 3, V E G F A$ ) and transcription factors or modulators (as NFE2L2, MAFF, HES1, FOSL1, TGIF1) and their expression resulted significantly modulated in at least 1 time point (Additional file 7: Table S4). In general, 

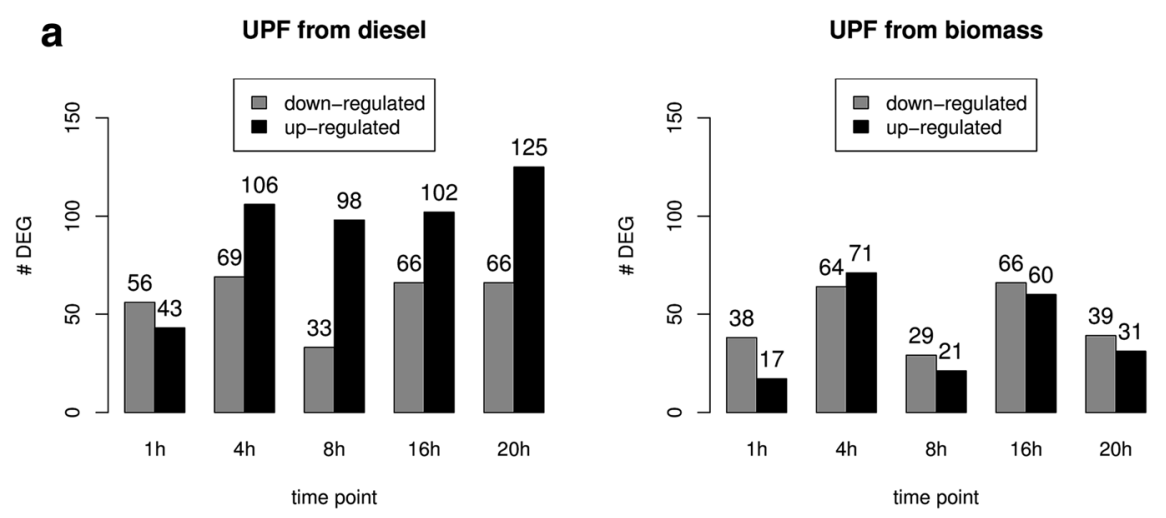

b
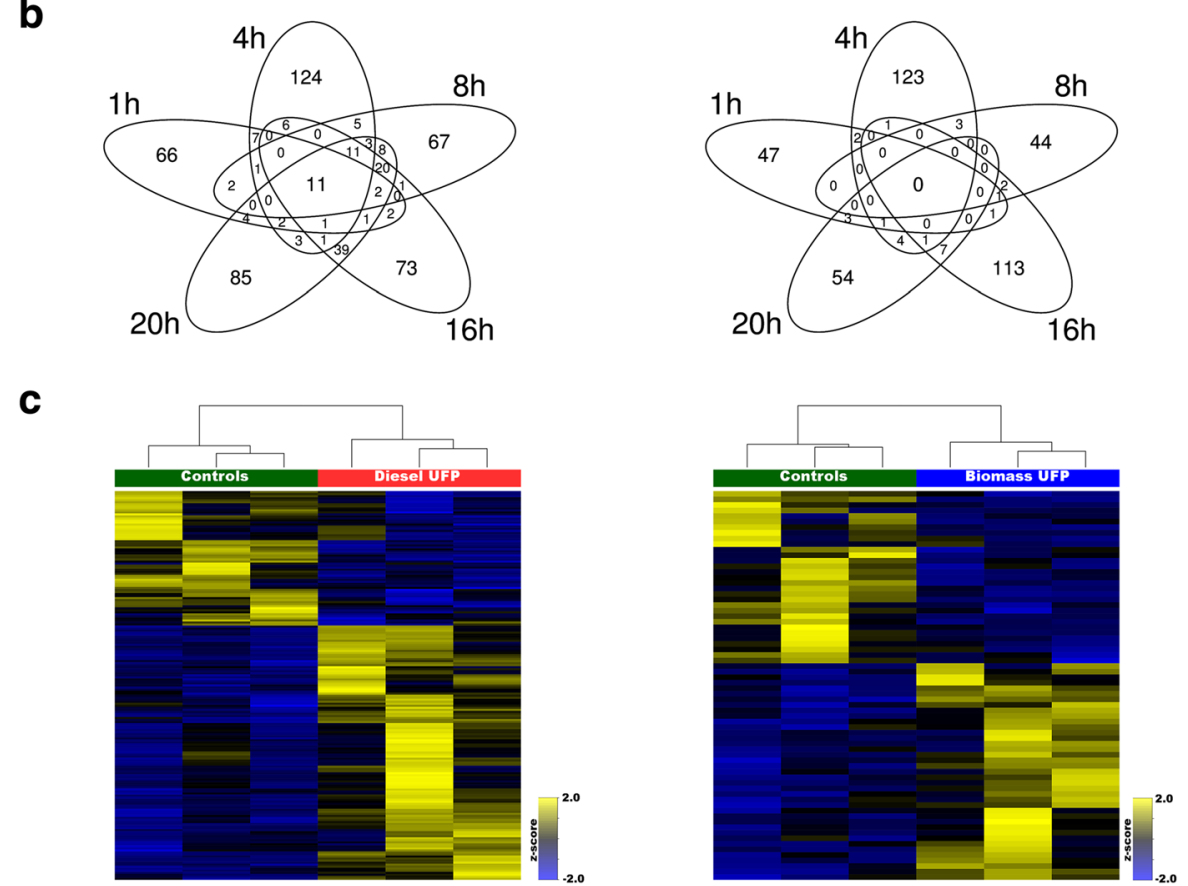

Fig. 1 Analysis of the transcriptional differences of BEAS-2B cells exposed to diesel (left panels) and biomass UFP (right panels) as compared to controls. a Number of differentially up- and down-regulated genes at each time point. b Overlap of DEGs identified at each time point. c Hierarchical clustering of the 191 and 70 genes differentially expressed after $20 \mathrm{~h}$ of exposure to diesel and biomass UFP, respectively

gene expression data from cells exposed to biomass UFP returned lower normalized enrichment scores (NES) and smaller number of DEGs in the core enrichment of modulated pathways indicating a milder modulation of hallmark gene sets by biomass as compared to diesel. For instance, none of the genes comprised in the core enrichment of the hypoxia pathway, the most enriched gene set after exposure to biomass UFP (Table 1), resulted significantly differentially expressed, suggesting a uniform but modest modulation induced by biomass UFP.

\section{Exposure to diesel and biomass UFP modulates transcriptional dynamics in BEAS-2B cells}

To capture variations in the transcriptional dynamics after exposure to diesel and biomass UFP, we identified genes showing statistically significant expression changes over time using the next-maSigPro method of the maSigPro $\mathrm{R}$ package [24, 25]. maSigPro revealed profound temporal changes in the expression of 120 and 96 genes in BEAS-2B cells exposed to diesel and biomass UFP, respectively, at a 95\% confidence level (Additional file 11: Table S7). Using hierarchical clustering and maSigPro default parameters, significant genes were grouped into nine clusters showing distinct expression profiles during the time of the experiment (Fig. 3 and Additional file 12: Figure S5 and Additional file 11: Table S7). Overall, we observed that exposure to diesel UFP exerted a stronger effect on the modulation of transcriptional dynamics in comparison with biomass UFP. Indeed, upon diesel exposure, four groups of genes (i.e., those comprised in 
Table 1 Top15 enriched gene sets in BEAS-2B cells after $20 \mathrm{~h}$ of exposure to UFP from diesel and biomass (FDR $\leq 0.05$ ). Gene sets are from the of the MSigDB hallmarks collection; size is the number of genes in the gene set and NES, the normalized enrichment score, accounts for the overrepresentation of a gene set at the top or bottom of a ranked list of genes. Positive NES indicates enrichment in treated samples, instead negative NES in controls

\begin{tabular}{|c|c|c|}
\hline Gene set & Size & NES \\
\hline \multicolumn{3}{|l|}{ Enriched in BEAS-2B cells exposed to diesel UFP } \\
\hline TNFA_SIGNALING_VIA_NFKB & 182 & 4.635 \\
\hline P53_PATHWAY & 185 & 3.383 \\
\hline HYPOXIA & 168 & 3.145 \\
\hline EPITHELIAL_MESENCHYMAL_TRANSITION & 173 & 3.063 \\
\hline XENOBIOTIC_METABOLISM & 141 & 2.814 \\
\hline COAGULATION & 80 & 2.723 \\
\hline ESTROGEN_RESPONSE_EARLY & 166 & 2.645 \\
\hline CHOLESTEROL_HOMEOSTASIS & 70 & 2.411 \\
\hline REACTIVE_OXIGEN_SPECIES_PATHWAY & 43 & 2.389 \\
\hline GLYCOLYSIS & 174 & 2.318 \\
\hline INFLAMMATORY_RESPONSE & 127 & 2.272 \\
\hline APICAL_JUNCTION & 150 & 2.270 \\
\hline G2M_CHECKPOINT & 197 & -2.819 \\
\hline PROTEIN_SECRETION & 92 & -3.075 \\
\hline E2F_TARGETS & 199 & -3.502 \\
\hline \multicolumn{3}{|c|}{ Enriched in BEAS-2B cells exposed to biomass UFP } \\
\hline HYPOXIA & 168 & 2.920 \\
\hline MTORC1_SIGNALING & 194 & 2.555 \\
\hline PROTEIN_SECRETION & 92 & 2.534 \\
\hline TNFA_SIGNALING_VIA_NFKB & 182 & 2.363 \\
\hline FATTY_ACID_METABOLISM & 130 & 2.350 \\
\hline ANDROGEN_RESPONSE & 89 & 2.337 \\
\hline G2M_CHECKPOINT & 197 & 2.335 \\
\hline E2F_TARGETS & 199 & 2.330 \\
\hline INTERFERON_GAMMA_RESPONSE & 158 & 2.263 \\
\hline MYC_TARGETS_V1 & 198 & 2.222 \\
\hline INFLAMMATORY_RESPONSE & 127 & 2.115 \\
\hline BILE_ACID_METABOLISM & 76 & 2.080 \\
\hline COMPLEMENT & 139 & 2.049 \\
\hline TGF_BETA_SIGNALING & 50 & 1.875 \\
\hline MYOGENESIS & 123 & -2.445 \\
\hline
\end{tabular}

clusters 4, 6, 7, and 9) showed a peak of expression at early time points $(4 \mathrm{~h}-8 \mathrm{~h})$; two clusters displayed an increasing trend over time after $8 \mathrm{~h}$ of exposure (clusters 2 and 5), while genes in cluster 3 and 8 had a sharp decrease of their expression level at $8 \mathrm{~h}$ (Fig. 3). In particular, cluster 9 presents some of the most up-regulated genes (as EPGN, GREM1, HMOX1, SERPINB2), cluster
2 comprises AHRR, CYP1A1, CXCL2, IRAK2, TNFAIP3, IL24, IL6, and VEGFA, while cluster 8 includes CYP1B1, MAFF, LIF, and TIPARP (Fig. 3). Upon exposure to biomass UFP, three groups of genes (clusters 1,4 , and 5) showed a peak of expression at early time points ( $4 \mathrm{~h}-8 \mathrm{~h}$ ) , while genes in clusters 7 and 9 increased their expression during the entire time course (Additional file 12: Figure S5). Annotation analysis of the gene groups highlighted that exposure to diesel UFP activated biological processes such as response to oxidative stress and blood vessels development while UFP from biomass exposure induced a significant enrichment in genes belonging to gene expression (data not shown).

\section{Reconstruction of the gene networks in BEAS-2B cells exposed to diesel and biomass UFP}

To extract regulatory relations we applied a gene network analysis to the gene expression data of BEAS-2B exposed to UFP. To build the regulatory networks we selected genes that were differentially expressed or present in the core enrichment of significantly enriched gene sets in at least one time point (Additional file 13: Table S8). The application of these criteria led to the reconstruction of the regulatory network only for cells exposed to UFP derived from diesel, while the low number of DEGs and of genes in the core enrichment of GSEA hampered the reconstruction of a network based on the transcriptional profile of cells exposed to biomass UFP. For cells exposed to diesel UFP, the network comprised 164 genes and 576 interactions, mainly representing "expression regulation", "activation" and "phosphorylation" types of regulation (Additional file 14: Table S9). The network architecture highlighted the presence of several interconnected sub-networks including several genes (nodes) interacting with many DEGs (Additional file 15: Figure S6).

Overall, we identified 42 node genes that, although not differentially expressed, displayed direct interactions with either up or down-modulated genes (Fig. 4). By literature mining we identified some interesting genes (as STAT3, HIF1a, NFKB1, KRAS) that have been reported to play an important role in biological processes as inflammation, EMT, coagulation and angiogenesis, which are at the basis for cancer and cardiovascular diseases. Overall, the gene network allowed discovering hidden regulators that may act up- and down-stream to modulate the expression of genes responsive to the exposure to UFP derived from diesel combustion.

\section{Validation of genes and proteins differentially expressed upon exposure to diesel UFP}

The differential expression of a set of DEGs, annotated in the biological processes of inflammation and oxidative stress, vasculature developments, was validated using qPCR (Table 2). The 23 selected targets were manually 

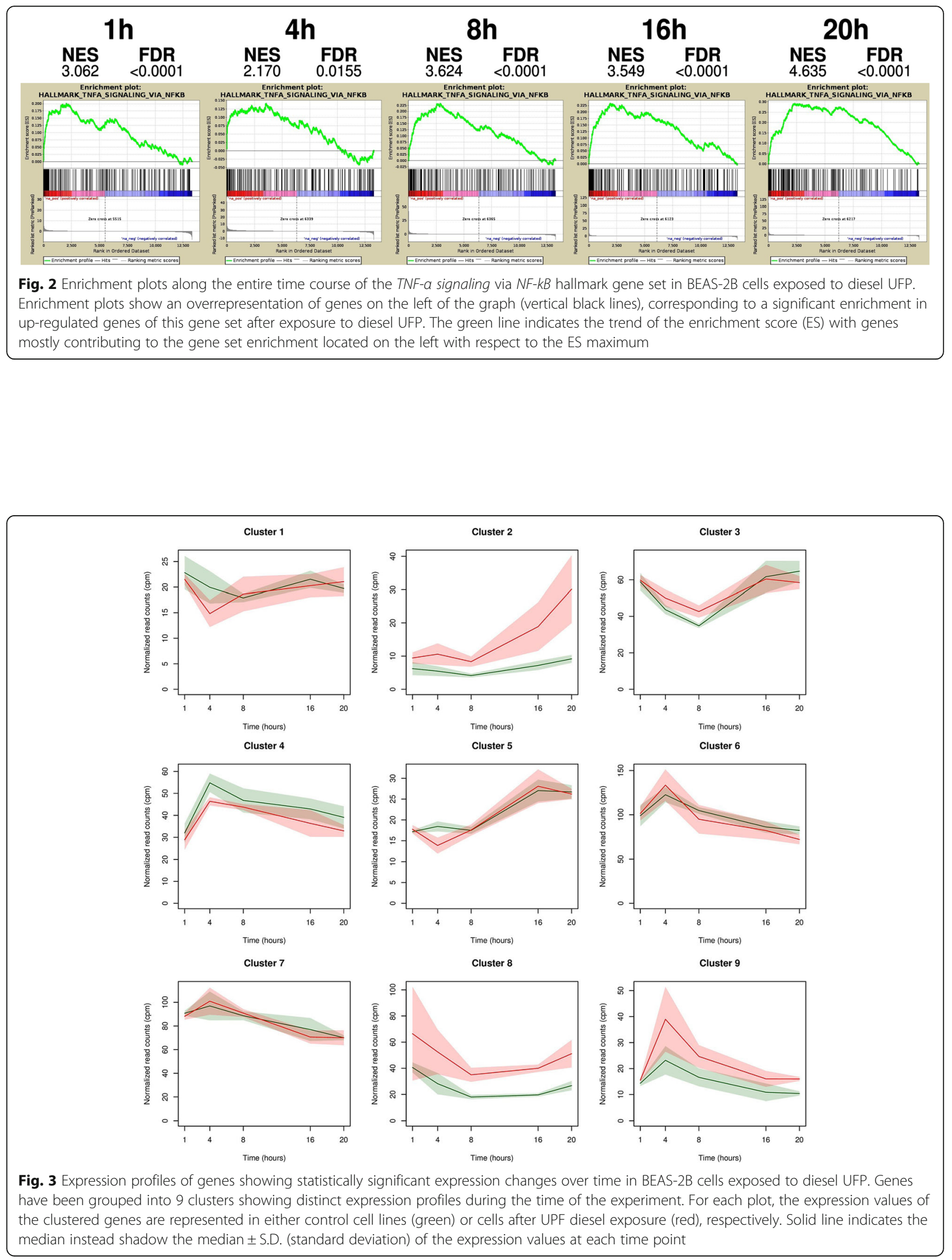


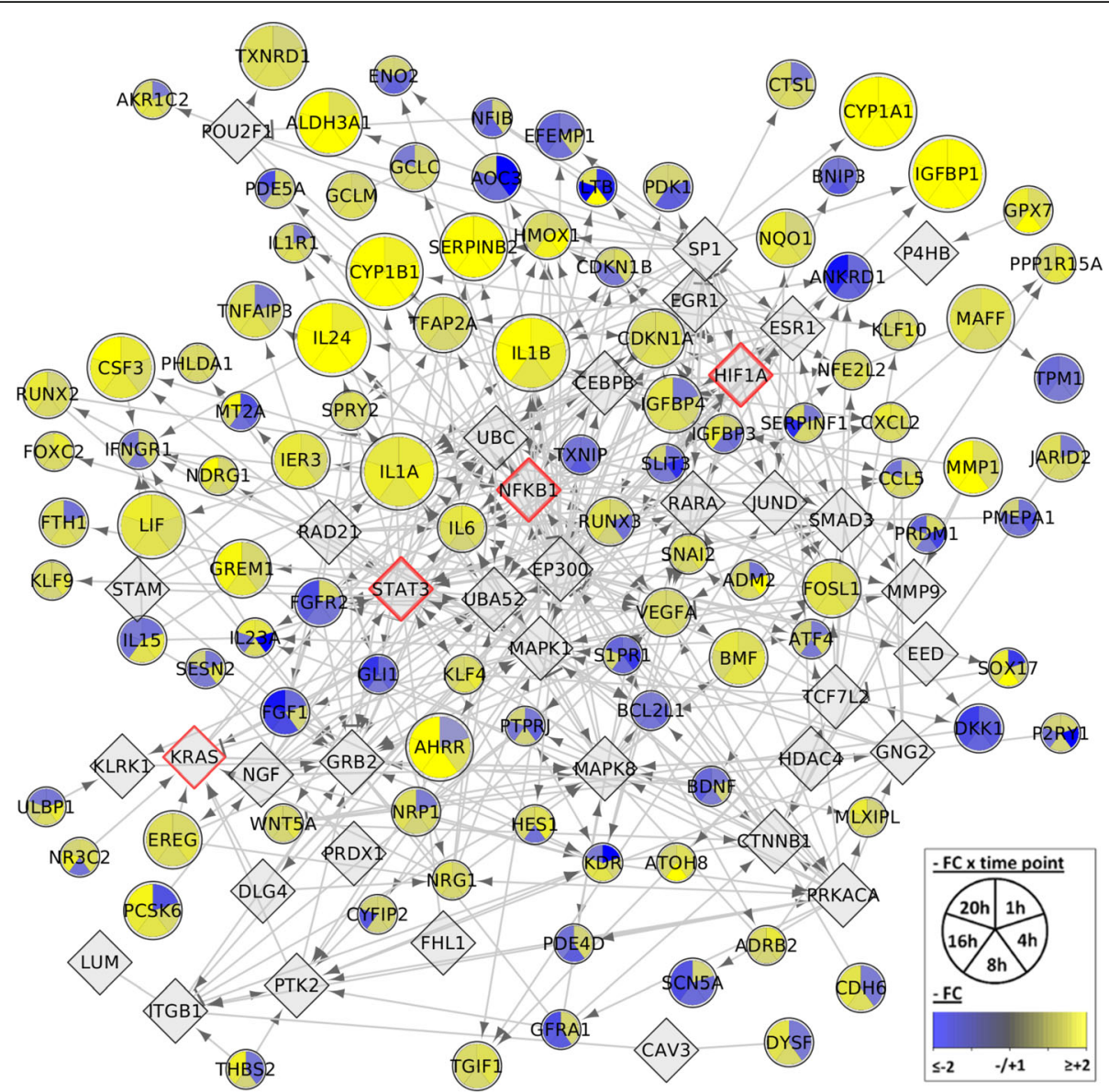

Fig. 4 Network analysis of selected DEGs in cells exposed to from diesel UFP. The initial 545 DEGs were filtered by the presence in the core enrichment of four significant hallmarks GSEA (TNF-a signaling via NF-KB, Inflammatory response, EMT, Xenobiotic metabolism) or by literature mining prioritization; (further details on DEGs selection are in section Material and Methods, and in Additional file 14: Table S9). Of the 129 resulting DEGs, network analysis identified a biological interaction for 122 genes (rounded shape) and 42 further "linker" genes (diamond shape). Some of the most interesting linker genes are investigated in the Discussion section (red board). Grey lines indicate manually curated interactions according to Reactome FI database. Size of DEGs nodes is directly proportional to the number of differentially expressed time points; the FC at each time point in cells exposed to UFP from diesel vs control is also indicated. The complete network inclusive of the predicted interactions is available as Additional file 15: Figure S6

chosen according to their inclusion in the gene set of next-maSigPro cluster and of GSEA hallmarks. Moreover, we proceeded with a deep literature mining analysis referring to specific keywords such as lung diseases, cardiovascular. Further details are reported in the legend of Table 2. Overall, qPCR results confirmed the expression patterns at $4,8,16,20$ h identified by RNA-seq in BEAS-2B exposed to diesel UFP and values from the two types of transcriptional assay resulted highly correlated across all time points (average Pearson correlation value of 0.75 between expression levels from RNA-seq and qPCR; Table 2). Alternatively to qPCR validation, to support the evidences of gene expression profiling and bioinformatics analyses, we quantified the release of four soluble factors, involved in the inflammatory signaling, cell proliferation and regulation of angiogenesis, in cells supernatants. In particular, we evaluated with ELISA assay the protein levels of IL-6, IL-24, EREG, and VEGFA in the protein lysate of BEAS-2B cells exposed to diesel and biomass UFP. As compared to cells exposed to the sole medium, cells exposed to UFP from diesel significantly increased the release of interleukins, IL-6 and MDA-7/ IL24, and of EREG and VEGF (Table 3). On the contrary, biomass UFP did not induce any significant modulation of the analyzed proteins (data not shown).

\section{Discussion}

In our study we designed and adopted a time course experiment to investigate, through RNA-seq, the transcriptional changes induced in human bronchial epithelial cells by the exposure to UFP from diesel and biomass combustion. The bioinformatics analysis of transcriptional data reveals that the two different UFP induce, since the earliest time points, different transcriptional 
Table 2 Comparison of qPCR versus RNA-seq of 23 selected DEGs in BEAS-2B cells exposed to diesel UFP. Numbers represent fold changes of separate experiments $(n=3)$ for each time point. Fold changes for both qPCR and RNA-seq are calculated considering exposed cells versus control cells after normalization. Pearson correlation between qPCR and RNA-seq FC for 4, 8, 16 and $20 \mathrm{~h}$ resulted in $0.759,0.772,0.715$ and 0.774 respectively

\begin{tabular}{|c|c|c|c|c|c|c|c|c|c|}
\hline \multirow[t]{2}{*}{$\overline{\text { Gene symbol }}$} & \multicolumn{4}{|c|}{$\mathrm{qPCR}(\mathrm{FC})$} & \multicolumn{4}{|c|}{ RNAseq $(F C)$} & \multirow[t]{2}{*}{ Biological annotations (GSEA $\left.{ }^{e}\right)$} \\
\hline & $4 \mathrm{~h}$ & $8 \mathrm{~h}$ & $16 \mathrm{~h}$ & $20 \mathrm{~h}$ & $4 \mathrm{~h}$ & $8 \mathrm{~h}$ & $16 \mathrm{~h}$ & $20 \mathrm{~h}$ & \\
\hline ALDH3A1 & 3.49 & 6.79 & 6.40 & 3.74 & 4.64 & 4.95 & 4.65 & 4.14 & Enzyme \\
\hline CCL5 & 1.78 & 1.78 & -1.04 & -1.71 & 1.85 & 1.19 & 1.63 & -1.16 & Secreted protein (NFK; INF) \\
\hline CDKN1A & 1.68 & 1.51 & 1.29 & 1.41 & 1.56 & 1.62 & 1.27 & 1.34 & Transcription factor (NFK; INF) \\
\hline$C X C L 2^{a}$ & -1.52 & -1.04 & 2.01 & 3.24 & 1.28 & 1.37 & 1.26 & 2.09 & Secreted protein (NFK; INF) \\
\hline$E P G N^{b}$ & 6.50 & 6.04 & 5.19 & 4.09 & 5.92 & 6.94 & 8.52 & 6.06 & Secreted protein \\
\hline FOSL1 & 1.37 & 1.87 & 1.94 & 1.27 & 1.29 & 1.75 & 1.70 & 1.98 & Transcription factor (NFK) \\
\hline GREM ${ }^{b}$ & 1.66 & 2.38 & 3.50 & 2.64 & 1.22 & 1.97 & 2.61 & 2.76 & Secreted protein (EMT) \\
\hline HES1 & 3.56 & 1.21 & 1.47 & 2.34 & 2.15 & -1.19 & 1.26 & 1.28 & Transcription factor (NFK) \\
\hline$H M O X 1^{b}$ & 3.70 & 2.95 & 2.51 & 2.34 & 3.46 & 2.48 & 1.16 & 1.35 & Enzyme (XEN) \\
\hline IER3 & 1.88 & 1.54 & 2.15 & 1.63 & 1.22 & 1.89 & 1.85 & 2.04 & Secreted (NFK) \\
\hline $\mid G F B P 1$ & 4.20 & 2.86 & 3.73 & 1.95 & 4.21 & 4.73 & 3.82 & 3.71 & Transcription factor (XEN) \\
\hline ILIA & 2.47 & 1.71 & 2.32 & 2.08 & 2.57 & 1.79 & 2.25 & 1.91 & Secreted protein (NFK;INF) \\
\hline $\operatorname{IL} 1 B$ & 2.10 & 2.60 & 3.70 & 5.30 & 2.16 & 1.83 & 3.73 & 3.49 & Secreted protein (NFK;INF) \\
\hline$L I^{C}$ & 1.86 & 1.72 & 1.98 & 1.74 & 1.36 & 1.69 & 1.84 & 2.25 & Secreted protein (NFK) \\
\hline$M A F F^{C}$ & 1.41 & 1.41 & 1.96 & 1.67 & 1.52 & 1.29 & 1.79 & 1.45 & Transcription factor (NFK) \\
\hline NFE2L2 & -1.76 & -1.08 & 1.26 & 1.94 & 1.64 & 1.26 & 1.28 & 1.13 & Transcription factor (NFK) \\
\hline PPP1R15A & 3.39 & 1.51 & -1.12 & 1.07 & 2.24 & 1.88 & 1.18 & 1.17 & ENZYME (NFK) \\
\hline SLC16A6 & 3.86 & 1.58 & 1.05 & 2.09 & 4.09 & 1.78 & 1.37 & 1.29 & Solute carrier (NFK) \\
\hline SLC7A5 & 1.57 & 2.28 & -1.08 & 2.90 & 1.25 & 1.82 & 1.77 & 1.98 & Solute carrier \\
\hline STC2 ${ }^{a}$ & 3.54 & 2.25 & 1.60 & 1.48 & 1.94 & 2.03 & 1.60 & 1.53 & Secreted factor \\
\hline TGIF1 & 2.37 & 1.41 & 1.15 & 1.18 & 1.77 & 1.23 & 1.34 & 1.34 & Transcription factor (NFK) \\
\hline TNFAIP3 ${ }^{a}$ & -1.12 & 1.22 & 2.33 & 2.26 & 1.01 & 1.72 & 1.76 & 1.48 & Transcription factor (NFK;INF) \\
\hline TXNRD $1^{b}$ & -1.04 & 1.92 & 1.57 & 2.14 & 1.43 & 1.54 & 1.51 & 1.55 & Enzyme \\
\hline
\end{tabular}

Gene included in next-maSigPro cluster analysis: ${ }^{a}$ cluster $2 ;{ }^{b}$ cluster $9 ;{ }^{c}$ cluster $8 ;{ }^{d}$ cluster 3

'GSEA hallmarks gene set legend: NFK TNF-a signaling via NF-kB, INF inflammatory response, XEN, xenobiotic metabolism, EMT, epithelial mesenchymal transition

dynamics resulting in the activation of specific genes and activation of some common molecular mechanisms, although at very different amplitudes.

The gene expression analysis evidenced that the exposure to diesel UFP induces a stronger modulation of gene transcription as compared to biomass in term of differentially

Table 3 Protein release of BEAS-2B cells exposed to diesel UFP for $20 \mathrm{~h}$ assessed by ELISA. Numbers represent mean \pm SEM of separate experiments $(n=6)$

\begin{tabular}{llll}
\hline Protein name & Control $(\mathrm{pg} / \mathrm{ml})$ & Diesel $(\mathrm{pg} / \mathrm{ml})$ & ANOVA test $^{*}$ \\
\hline IL-6 $^{\text {a }}$ & $158 \pm 14.7$ & $289 \pm 15.7$ & 0.006 \\
IL-24 $^{\text {a }}$ & $113 \pm 11.6$ & $196 \pm 30.9$ & 0.041 \\
EREG & $130 \pm 2.9$ & $196 \pm 4.2$ & 0.032 \\
VEGFA $^{\text {a }}$ & $224 \pm 36.2$ & $356 \pm 40.7$ & 0.037 \\
\hline
\end{tabular}

*One Way ANOVA (Bonferroni and Dunnett's), $p<0.05$ compared to untreated cells

a gene temporally modulated in cluster 2 (see Additional file 11: Table S7) expressed genes, temporal patterns, and pathway activation. We can hypothesized that this difference is connected to the different physicochemical properties of the two types of UFPs. Indeed, in a previous paper [7], we showed that diesel particles are characterized by the presence of PAHs associated with diesel soot, such as pyrene, phenanthrene, benzo[a]anthracene and dibenzo[a,h]anthracene, while biomass particles are enriched in fluoranthene and pyrene. Moreover, we demonstrated that metals are present at higher concentrations in diesel samples as compared to biomass ones. These compounds have been indicated as the main contributors to the effects induced by the combustion particles and differences in their relative content have been suggested to explain the variability of the toxicological responses elicited by such particles [5, 31]. Although a direct association of the different physicochemical properties and the diverse transcriptional effects is still speculative, the previously reported evidences might partly explain the 
stronger biological response induced by the exposure to diesel UFP.

Bioinformatics analysis allowed the identification of 11 genes significantly induced just $1 \mathrm{~h}$ after exposure to diesel UFP and remained constantly over-expressed along the entire time course. This immediate and extended modulation indicates that cell responses are activated shortly after the exposure, and sustained in time. The most modulated genes by diesel UFP were functionally annotated to xenobiotic metabolism (CYP1A1, CYP1B, and TIPARP) and inflammatory response (IL24, EPGN, IL1A, and IL1B). The expression of these genes was also induced by biomass UFP, but at a much lower extent and at later time points (Additional file 6: Table S3). Since PAHs activate the transcription of genes of the xenobiotic metabolism after binding the $A h R$ transcription factor [32], these results are concordant with the higher content of PAHs in diesel particles. Several studies reported that $A h R$ activation and CYP enzymes increase in in vitro and in vivo models exposed to diesel particles [9,33], while, to our knowledge, data on biomass and wood particles effects are still lacking. Bonvallot et al. [34] have reported the induction of CYP1A1 gene expression in $16 \mathrm{HBE}$ cells treated with native diesel particles and their organic extracts, but not with stripped particles, showing that the organic compounds are responsible for this over-expression. A more recent study has investigated different diesel samples and found that particles with higher PAHs content were more effective in inducing CYP1A1 and markers of inflammation and oxidative stress [35]. The same authors analyzed also inflammatory markers, in particular $I L 1 B$, in monocytes exposed to traffic-derived, wood, and commercial diesel particles, reporting differences in activated signaling pathways in relation to the particle chemical composition [36].

Functional enrichment analysis revealed that both types of particles activate some common molecular mechanisms, although at very different amplitudes. As compared to biomass, exposure to diesel UFP determined higher enrichment scores of biologically relevant gene sets and a larger number of differentially expressed genes in the core enrichment of the modulated pathways. For instance, both diesel and biomass up-regulated genes comprised in the gene sets of TNF- $\alpha$ signaling via $N F-k B$, inflammatory response, and hypoxia but only the exposure to diesel UFP induced this up-regulation along the entire time course. Among the genes belonging to the core enrichments of the TNF- $\alpha$ signaling via NF-kB pathway (Fig. 2) and exerting a profound temporal expression changes by diesel UFP some were confirmed at RNA and protein levels (Tables 2 and 3). By literature mining, we found that these genes of TNF- $\alpha$ signaling via NF- $k B$ pathway are involved in human diseases such as lung cancer, respiratory, and cardiovascular dysfunctions (Additional file 13: Table S8).
Interestingly, TNF- $\alpha$ is an inflammatory mediator, which has a tumor-promoting role in various stages of carcinogenesis, induces EMT mediated by TGF- $\beta$, promotes angiogenesis through the release of $V E G F$, and activates $N F-k B$ signaling in models of cancer [37]. Inflammatory mediators as CCL5, CXCL2, and some interleukins (e.g. IL6, IL8) contribute to several human diseases through processes including inflammation and angiogenesis [37]. Several studies have shown that exposure to diesel particles and to some diesel compounds (e.g. 1-nitropyrene) triggers the release of such mediators in vitro and in vivo [38-40]. Release of LIF, IL6, and ILIB has been also observed in alveolar and bronchial cells exposed to ambient PM [41]. IL6 is a well-known marker of diesel and airborne PM exposure, and it has been already suggested to contribute to particles-induced cardiovascular and respiratory diseases [1].. NFE2L2 (NRF2) is an important transcription factor activated by high ROS levels. It regulates genes involved in oxidative stress, inflammation and injury response, and has a protective role in lung and cardiac diseases [42]. In accordance with a recent paper on gene expression modulation after PM exposure [43], our data have shown that diesel exposure regulates many NFE2L2 target genes involved in glutathione synthesis $(G C L M)$, cysteine-glutamate transporter (SLC7A11) and antioxidant response (HMOX1, TXNRD1, and NQO1). VEGF (VEGFA) is a pro-angiogenic factor with multifunctional roles, including the regulation of both physiological and pathological angiogenesis and vascular remodeling, promoting endothelial cells proliferation and cell migration $[44,45]$. It has been reported that an increased expression of VEGF, at the mRNA and protein level, in A549 and BEAS-2B cells, occurs after the exposure to external stimuli such as IL1B, TNF- $\alpha$ and lipopolysaccharide (LPS) [46]. This event suggests that pulmonary inflammation contributes to the up-regulation and release of VEGF from lung epithelial cells with consequent modulation of lung endothelial cells function and permeability [46]. A recent work from Tseng et al. [47] has reported that endothelial cells exposed to diesel particles release VEGF through the induction of intracellular ROS formation and the secretion of the pro-inflammatory cytokines TNF- $\alpha$ and IL6. VEGF together with other markers, such as MMPs, HO-1 and ET-1, correlates with the development of atherosclerotic plaque and angiogenesis in mice following exposure to ultrafine PM [48] and diesel particles [49-51]. Noticeably, in diesel we obtained a significant enrichment also for the EMT gene set (Table 1). Since EMT is an important step in the carcinogenic process, this result further supports the tumorigenic potential of exposure to diesel UFP [52] These observations indicate that diesel particles might contribute to the carcinogenic potential of fine PM [53] at least in cities where traffic contribution to air pollution is relevant. 
To extract regulatory connections from the gene expression data, we applied a gene regulatory network analysis and, at least for the exposure to diesel UFP, we discovered some hidden regulators that may act up- and down-stream to modulate the expression of genes responsive to diesel exposure (Fig. 4 and Additional file 15, Figure S5). Among the regulators, we have found the transcription factor STAT3, which is activated by pathways involved in inflammation, angiogenesis, and epithelial remodeling [54], and participates in several physiologic cellular function such as proliferation, differentiation, and apoptosis $[55,56]$. STAT3 activation also contributes to pathological processes as oncogenesis, by augmenting tumor invasion and angiogenesis [57, 58]. Cao and coworkers [59] reported the activation of STAT3 in bronchial epithelial cells exposed to diesel exhaust. STAT3 target genes include HES1, HMOX1, IL6, IL24 and VEGF, whose modulation has been validated here by qPCR (Table 2) and at protein level (Table 3 ). The hypoxia inducible-factor-1a (HIF1a), another relevant node of the reconstructed gene network, can also induce VEGF transcription, and both these genes were previously found modulated in HUVEC cells exposed to diesel [50]. Consistently with the functional enrichments analyses that highlighted the role of $T N F-\alpha$ signaling via $N F-k B$, the gene network pointed out to the transcription factor NFKB1 (a subunit of the NF-kB complex), previously reported to be activated upon diesel exposure [11]. NFKB1 has been related to the carcinogenic process through its biological role as cell survival, differentiation, inflammation, and growth [15, 60]. Recently, it has been demonstrated that UFP from vehicular traffic promotes vascular calcification via $N F-\kappa B$ signaling activation [61], indicating its possible contribution to cardiovascular diseases. Moreover, the gene network analysis identified, as a relevant node, the oncogene $K R A S$, that was demonstrated to induce the overexpression of EREG [62], a protein that we found to be significantly released by cells exposed to diesel UFP. To our knowledge, EREG modulation has never been reported before in cells exposed to diesel UFP, although we previously reported its release in BEAS-2B and A549 cells exposed to PM $[17,63]$. These findings might have a significant role in relation to diesel and PM carcinogenic potency, since deregulation of EREG is known to contribute to the progression of different cancers, including lung, and to lead to an aggressive phenotype and an unfavorable prognosis in KRAS-mutant non-small-cell lung carcinoma (NSCLC) [62, 64]'. Overall, the network reconstruction indicated the presence of transcription factors that might activate novel signaling pathways in BEAS-2B cells at diesel exposure.

Nonetheless, the present investigation presents some limitations. BEAS-2B is a cell line commonly used in in vitro models to investigate the potential effect of PM and other airborne pollutants on human bronchial epithelia $[65,66]$. However, the use of mono cell culture has clearly disadvantages (e.g. might represent a simplification of the real conditions, lacking the airway multicellular barriers and the air surface liquid secreted by the lung epithelial cells). Recently, systems with cells cultured at Air Liquid Interface (ALI) received considerable attention as an alternative method to expose epithelial cells when investigating the biological effects of ultrafine particle matters $[67,68]$. However, studies based on ALI exposure systems still benefit of further experimental validations before able to replace conventional culture condition in air pollution toxicological studies. In the present study, BEAS-2B cells have been exposed to a low dose of UFP $\left(2.5 \mu \mathrm{g} / \mathrm{cm}^{2}\right)$ that, although lower than what reported by Schwarze and co-workers [8], is similar to the deposition dose calculated by $\mathrm{Li}$ et al. [69] for the tracheobronchial region. Indeed, starting from an environmental concentration of $79 \mu \mathrm{g} / \mathrm{m}^{3} / 24 \mathrm{~h}, \mathrm{Li}$ and collaborators indicated that the real life daily exposure might determine a deposition of $\mathrm{PM}_{2.5}$ particles up to $200 \mu \mathrm{g} / \mathrm{cm}^{2}$ in the nasopharyngeal tract and up to $2.3 \mu \mathrm{g} / \mathrm{cm}^{2}$ in the tracheobronchial region in persons with healthy conditions. During the winter season, the metropolitan area of Milan might experience environmental concentrations that exceed the level of $79 \mu \mathrm{g} / \mathrm{m}^{3} / 24 \mathrm{~h}$ (Regional Environmental Protection Agency ARPA Lombardia) and, thus, the deposition of $\mathrm{PM}_{2.5}$ particles in the tracheobronchial region might be higher than the dose adopted here. Nevertheless, transcriptional profiles of cells exposed at this dose indicate that even a low UFP concentration induces a transcriptional modulation. In this respect, we believe that the conditions we selected in our experimental design, although not perfectly mimicking what experienced in a real setting, still constitute an adequate working scenario to recapitulate the impact on human health of UFP from the selected sources of emission.

\section{Conclusions}

Altogether, these data provide new insights into UFP toxicity and shed new light on possible biochemical mechanisms by means of which these particles may act as carcinogens and harmful factors for human cardiovascular disease. In this direction, we think that future investigation should focus on the functional role of genes such as STAT3, HIF1a, NFKB1 and KRAS that have emerged as major regulators from the network analysis. An adequate understanding of the mechanisms activated by ambient particles will enable in the future to improve knowledge in the field of PM risk assessment as well as the setting of new strategies towards health protection. 


\section{Additional files}

Additional file 1: Figure S1. TEM image of diesel particles before (A) and after (B) sonication and resuspension. (PDF $1534 \mathrm{~kb}$ )

Additional file 2: Figure S2. Alamar Blue viability test of BEAS-2B exposed to increasing concentrations of diesel and biomass UFP. Alamar blue assay (Alamar Blue ${ }^{\circledR}$ Reagent, Catalog nr. DAL1025) was performed according to manufacturers' instructions. Alamar Blue is a non-toxic dye that changes its colour when active cells metabolize it. Cells viability was proportionally related to the colour of the reagent and it was expressed as percentage (\%) of living cells respect to control samples (untreated cells, 100\%).The experiments were replicate 3 times and results are expressed as mean percent \pm SEM of viable cells in comparison to controls (untreated cells). (PDF 92 kb)

Additional file 3: Table S1. Total number of reads and number and percentage of reads mapped by TopHat in each analyzed sample. (XLS 39 kb)

Additional file 4: Figure S3. Distributions of normalized cpm counts (in log2) for the 13.309 genes passing the expression filter. The uniform distribution of read counts across all 45 samples supports the elevate quality of sequencing data. Sample IDs are in Additional file 3: Table S1. (PDF 549 kb)

Additional file 5: Table S2. FC and $p$-value of the genes differentially expressed after exposure to UFP from diesel combustion (as compared to controls) at the different time points. (XLS $3855 \mathrm{~kb}$ )

Additional file 6: Table S3. FC and p-value of the genes differentially expressed after exposure to UFP from biomass combustion (as compared to controls) at the different time points. (XLS $3855 \mathrm{~kb}$ )

Additional file 7: Table S4. Fold change of genes differentially expressed by the exposure to both diesel and biomass UFP. (XLS 67 kb)

Additional file 8: Figure S4. Temporal variation of fold changes for the 11 genes that displayed a statistically significant up-regulation along the entire time course of BEAS-2B cells, exposed to diesel UFP. (PDF $232 \mathrm{~kb}$ )

Additional file 9: Table S5. Functional enrichment of gene sets from GSEA Hallmarks collection in cells exposed to diesel UFP. (XLS 48 kb)

Additional file 10: Table S6. Functional enrichment of gene sets from GSEA Hallmarks collection in cells exposed to biomass UFP. (XLS 49 kb)

Additional file 11: Table S7. Genes identified by maSigPro as differentially modulated in time during the exposure to biomass or diesel UFP, respectively. (XLS $66 \mathrm{~kb}$ )

Additional file 12: Figure S5. Expression profiles of genes showing statistically significant expression changes over time in BEAS-2B cells exposed to biomass UFP. Genes have been grouped into 9 clusters showing distinct expression profiles during the time of the experiment. For each plot, the expression values of the clustered genes are represented in either control cell lines (green) or cells after UPF biomass exposure (blue), respectively. Solid line indicates the median instead shadow the median \pm S.D. (standard deviation) of the expression values at each time point. (PDF $330 \mathrm{~kb}$ )

Additional file 13: Table S8. Detail of the filtering criteria for each of the DEGs from network analysis (Fig. 4); for each gene, the number of significant time points, presence in the core enrichment of the selected GSEA hallmarks or the number of Pubmed publications with cardiovascular diseases, lung cancer, or lung diseases terms are indicated. (XLS $78 \mathrm{~kb}$ )

Additional file 14: Table S9. Biological interactions of genes from network analysis (Fig. 4 and Additional file 15: Figure S6) according to the Reactome FI database; for each interaction, the type of regulation and the score are indicated. Scores range from 0 to 0.99 for predicted while are equal to 1 for manually annotated interactions. (XLS $123 \mathrm{~kb}$ )

Additional file 15: Figure S6. Complete network from Fig. 4 inclusive of predicted and manually curated interactions according to the Reactome FI database (see Additional file 14: Table S9), respectively as dashed or grey lines. As for Fig. 4, size of DEGs nodes is directly proportional to the number of differentially expressed time points; the FC at each time point in cells exposed to UFP from diesel vs control is also indicated. (PDF $1247 \mathrm{~kb}$ )

\section{Abbreviations}

AhR: Aryl hydrocarbon receptor; ARPA: Regional Environmental Protection Agency; DEGs: Differentially expressed genes; EMT: Epithelial mesenchymal transition; Fl: Functional Interaction; glm: Generalized linear model; GSEA: Gene Set Enrichment Analysis; INF: Inflammatory response; LPS: Lipopolysaccharide; NES: Normalized enrichment scores; NFK: TNF alfa signaling via NFKB; NSCLC: Non-small-cell lung cancer; PAHs: Polycyclic aromatic hydrocarbons; PM: Particular matter; qPCR: Quantitative Polymerase Chain Reaction; ROS: Reactive oxygen species; TEM: Transmission electron microscopy; UFP: Ultrafine particles; XEN: Xenobiotic metabolism

\section{Acknowledgements}

We thank the Doctorate program of Molecular and Translational Medicine (University of Milan) supporting the research of A.G. We acknowledge Roberta Bordoni (ITB-CNR Segrate, Milan, Italy) for her assistance for qPCR analysis. The authors are grateful to the Institute of Biomedical Technologies (ITB-CNR, Segrate, Milan, Italy) for technical support.

\section{Funding}

This study has been supported by Cariplo Foundation (Grant no. 2013-1038). This was also supported by the Epigenetics Flagship project CNR-MIUR grant (to S.B). The funders had no role in the study design, data collection and analysis, decision to publish, or preparation of the manuscript.

\section{Availability of data and materials}

All the data discussed in this study are available as the main figures and Supplementary data. The datasets RNA-seq raw and processed data generated during the current study are available in the Array Express archive under the accession number E-MTAB-5157 [http://www.ebi.ac.uk/arrayexpress/experiments/E-MTAB-5157].

\section{Authors' contributions}

EL, RB, LC performed the analyses of UFP treated BEAS-2B cell lines and carried out ELISA assays. MCP prepared RNA samples for RNA-seq analysis and performed $\mathrm{QPCR}$ analyses. AG, MF and CB performed the bioinformatics analysis for RNA-seq and qPCR data. AG, CB, EL, MG, RB interpreted the biological data. AG, $C B, E L, M G, R B, S B$ wrote the manuscript. CB and MC planned and supervised the project. All authors reviewed, read and approved the manuscript.

\section{Ethics approval and consent to participate}

Not-applicable.

\section{Competing interests}

The authors declare that they have no competing interests.

\section{Publisher's Note}

Springer Nature remains neutral with regard to jurisdictional claims in published maps and institutional affiliations.

\section{Author details}

${ }^{1}$ Department of Life Sciences, Center for Genome Research, University of Modena and Reggio Emilia, Via G. Campi 287, 41125 Modena, Italy. ${ }^{2}$ PhD Program of Molecular and Translational Medicine, Department of Medical Biotechnology and Translational Medicine, University of Milan, 20090 Segrate, Italy. ${ }^{3}$ Polaris Research Centre, Department of Earth and Environmental Sciences, University of Milano-Bicocca, Piazza della Scienza 1, 20126 Milan, Italy. ${ }^{4}$ Department of Physiopathology and Transplantation, University of Milan, Via Fratelli Cervi 93, 20090 Segrate, Italy. ${ }^{5}$ Unit of Environmental Chemistry and Interaction with Life (UCEIV, EA 4492), Université du Littoral Côte d'Opale 189A, Avenue Maurice Schumann, F-59140 Dunkerque, France. ${ }^{6}$ Italian National Agency for New Technologies, Energy and Sustainable Economic Development - ENEA SSPT-MET-INAT, Via Martiri di Monte Sole 4, 40129 Bologna, Italy. ${ }^{7}$ Department of Medical Biotechnology and Translational Medicine (BIOMETRA), University of Milan, Via Fratelli Cervi 93, 20090 Segrate, Italy. ${ }^{8}$ Institute for Biomedical Technologies, National Research Council (ITB-CNR), Via Fratelli Cervi 93, 20090 Segrate, Italy. 


\section{Received: 8 September 2017 Accepted: 16 April 2018} Published online: 27 April 2018

\section{References}

1. Nemmar A, Holme JA, Rosas I, Schwarze PE, Alfaro-Moreno E. Recent advances in particulate matter and nanoparticle toxicology: a review of the in vivo and in vitro studies. Biomed Res Int. 2013;2013:1-22. [cited $2015 \mathrm{Apr}$ 8]. Available from: http://www.hindawi.com/journals/bmri/2013/279371/

2. Lewtas J. Air pollution combustion emissions: characterization of causative agents and mechanisms associated with cancer, reproductive, and cardiovascular effects. Mutat Res. 2007;636:95-133. [cited 2015 Dec 3]. Available from: http://www.ncbi.nlm.nih.gov/pubmed/17951105

3. Miller MR, Shaw CA, Langrish JP. From particles to patients: oxidative stress and the cardiovascular effects of air pollution. Futur Cardiol. 2012;8:577-602. [cited 2016 Jun 24]. Available from: http://www.ncbi.nlm.nih.gov/pubmed/22871197

4. Mills NL, Miller MR, Lucking AJ, Beveridge J, Flint L, Boere AJF, et al. Combustionderived nanoparticulate induces the adverse vascular effects of diesel exhaust inhalation. Eur Heart J. 2011;32:2660-71. Oxford University Press; [cited 2016 Jun 27]. Available from: http://www.ncbi.nlm.nih.gov/pubmed/21753226

5. Cassee FR, Héroux M-E, Gerlofs-Nijland ME, Kelly FJ. Particulate matter beyond mass: recent health evidence on the role of fractions, chemical constituents and sources of emission. Inhal Toxicol. 2013;25:802-12. [cited 2015 Apr 8]. Available from: http://www.pubmedcentral.nih.gov/ articlerender.fcgi?artid=3886392\&tool=pmcentrez\&rendertype=abstract

6. Zheng M, Cass GR, Ke L, Wang F, Schauer JJ, Edgerton ES, et al. Source apportionment of daily fine particulate matter at Jefferson street, Atlanta, GA, during summer and winter. J Air Waste Manage Assoc. 2007;57:228-42. [cited 2016 Dec 23]. Available from: http://www.ncbi.nlm.nih.gov/pubmed/17355084

7. Longhin E, Gualtieri M, Capasso L, Bengalli R, Mollerup S, Holme JA, et al. Physico-chemical properties and biological effects of diesel and biomass particles. Environ Pollut. 2016;215:366-75. Available from: http://linkinghub. elsevier.com/retrieve/pii/S0269749116303943

8. Schwarze PE, Totlandsdal Al, Låg M, Refsnes M, Holme JA, Øvrevik J. Inflammation-related effects of diesel engine exhaust particles: studies on lung cells in vitro. Biomed Res Int. 2013;2013:1-13. Available from: https://doi.org/10.1155/2013/685142

9. Pálková L, Vondráček J, Trilecová L, Ciganek M, Pěnčíková K, Neča J, et al. The aryl hydrocarbon receptor-mediated and genotoxic effects of fractionated extract of standard reference diesel exhaust particle material in pulmonary, liver and prostate cells. Toxicol Vitr. 2015;29:438-48. Available from: http://www.ncbi.nlm.nih.gov/pubmed/25500124

10. Xia M, Viera-Hutchins L, Garcia-Lloret M, Noval Rivas M, Wise P, McGhee SA, et al. Vehicular exhaust particles promote allergic airway inflammation through an aryl hydrocarbon receptor-notch signaling cascade. J Allergy Clin Immunol. 2015;136:441-53. [cited 2016 Jan 11]. Available from: http://www.ncbi.nlm.nih.gov/pubmed/25825216

11. Totlandsdal Al, Cassee FR, Schwarze P, Refsnes M, Låg M. Diesel exhaust particles induce CYP1A1 and pro-inflammatory responses via differential pathways in human bronchial epithelial cells. Part Fibre Toxicol. 2010;7:41. BioMed Central; [cited 2015 Nov 17]. Available from: http://particleandfibretoxicology.biomedcentral.com/articles/10. 1186/1743-8977-7-41

12. Mutlu GM, Green D, Bellmeyer A, Baker CM, Burgess Z, Rajamannan N, et al. Ambient particulate matter accelerates coagulation via an IL-6-dependent pathway. J Clin Invest. 2007;117:2952-61. American Society for Clinical Investigation; [cited 2016 Jun 28]. Available from: http://www.ncbi.nlm.nih. gov/pubmed/17885684

13. Budinger GRS, McKell $J \mathrm{~L}$, Urich D, Foiles N, Weiss I, Chiarella SE, et al. Particulate matter-induced lung inflammation increases systemic levels of PAI-1 and activates coagulation through distinct mechanisms. PLoS One. 2011;6:e18525. Morty RE, editor. [cited 2016 Jun 28]. Available from: http:// www.ncbi.nlm.nih.gov/pubmed/21494547

14. Nemmar A, Subramaniyan D, Ali BH. Protective effect of curcumin on pulmonary and cardiovascular effects induced by repeated exposure to diesel exhaust particles in mice. PLoS One. 2012;7:e39554. Rojas M, editor. [cited 2016 Jun 28]. Available from: http://www.ncbi.nlm.nih.gov/pubmed/22745783

15. Valavanidis A, Vlachogianni T, Fiotakis K, Loridas S. Pulmonary oxidative stress, inflammation and cancer: respirable particulate matter, fibrous dusts and ozone as major causes of lung carcinogenesis through reactive oxygen species mechanisms. Int J Environ Res. 2013;10:3886-907. Public Health. [cited 2016 Apr 5]. Available from: http://www.mdpi.com/1660-4601/10/9/3886/
16. Huang $\mathrm{Y}$-CT. The role of in vitro gene expression profiling in particulate matter health research. J Toxicol Environ Health B Crit Rev. 2013;16:381-94. Available from: http://www.tandfonline.com/doi/abs/10.1080/10937404.2013.832649

17. Gualtieri M, Longhin E, Mattioli M, Mantecca P, Tinaglia V, Mangano E, et al. Gene expression profiling of A549 cells exposed to Milan PM2.5. Toxicol Lett. 2012;209:136-45.

18. Bolger AM, Lohse M, Usadel B. Trimmomatic: a flexible trimmer for Illumina sequence data. Bioinformatics. 2014;30:2114-20. [cited 2018 Jan 24]. Available from: http://www.ncbi.nlm.nih.gov/pubmed/24695404

19. Kim D, Pertea G, Trapnell C, Pimentel H, Kelley R, Salzberg SL. TopHat2: accurate alignment of transcriptomes in the presence of insertions, deletions and gene fusions. Genome Biol. 2013;14:R36. Available from: http://www.pubmedcentral.nih.gov/articlerender.fcgi?artid=4053844\&tool= pmcentrez\&rendertype $=$ abstract

20. Anders S, Pyl PT, Huber W. HTSeq-a Python framework to work with highthroughput sequencing data. Bioinformatics. 2015;31:166-9. Available from: https://academic.oup.com/bioinformatics/article-lookup/doi/10.1093/ bioinformatics/btu638

21. Robinson MD, McCarthy DJ, Smyth GK. edgeR: a Bioconductor package for differential expression analysis of digital gene expression data. Bioinformatics. 2010;26:139-40. Available from: http://www.ncbi.nlm.nih.gov/ pubmed/19910308\%5Cn. http://www.pubmedcentral.nih.gov/articlerender. fcgi?artid=PMC2796818

22. Chen J, Bardes EE, Aronow BJ, Jegga AG. ToppGene Suite for gene list enrichment analysis and candidate gene prioritization. Nucleic Acids Res. 2009;37:W305-11. Available from: https://academic.oup.com/nar/articlelookup/doi/10.1093/nar/gkp427

23. Becker KG, Hosack D a, Dennis G, Lempicki R a, Bright TJ, Cheadle C, et al. PubMatrix: a tool for multiplex literature mining. BMC Bioinformatics. 2003;4:61.

24. Subramanian A, Tamayo P, Mootha VK, Mukherjee S, Ebert BL, Gillette M, et al. Gene set enrichment analysis: a knowledge-based approach for interpreting genome-wide expression profiles. Proc Natl Acad Sci U S A. 2005;102:15545-50. Available from: http://www.ncbi.nlm.nih.gov/entrez/ query.fcgi?cmd=Retrieve\&db=PubMed\&dopt=Citation\&list_uids=16199517

25. Conesa A, Nueda MJ, Ferrer A, Talón M. maSigPro: a method to identify significantly differential expression profiles in time-course microarray experiments. Bioinformatics. 2006;22:1096-102. Available from: https:// academic.oup.com/bioinformatics/article-lookup/doi/10.1093/ bioinformatics/btl056

26. Nueda MJ, Tarazona S, Conesa A. Next maSigPro: updating maSigPro bioconductor package for RNA-seq time series. Bioinformatics. 2014;30: 2598-602. [cited 2016 Aug 30]. Available from: http://www.ncbi.nlm.nih.gov/ pubmed/24894503

27. Shannon P, Markiel A, Ozier O, Baliga NS, Wang JT, Ramage D, et al. Cytoscape: a software environment for integrated models of biomolecular interaction networks. Genome Res. 2003;13:2498-504. Available from: http:// www.genome.org/cgi/doi/10.1101/gr.1239303

28. Wu G, Dawson E, Duong A, Haw R, Stein L. ReactomeFIViz: a Cytoscape app for pathway and network-based data analysis. F1000 Res. 2014;3:146. [cited 2016 Jul 25]. Available from: http://www.ncbi.nlm.nih.gov/pubmed/25309732

29. Wu G, Feng X, Stein L. A human functional protein interaction network and its application to cancer data analysis. Genome Biol. 2010;11:R53. Available from: http://genomebiology.biomedcentral.com/articles/10. 1186/gb-2010-11-5-r53

30. Morris JH, Kuchinsky A, Ferrin TE, Pico AR. enhancedGraphics: a Cytoscape app for enhanced node graphics. F1000Res. 2014;3:147. Available from: http://f1000research.com/articles/3-147/v1

31. Li R, Ning Z, Majumdar R, Cui J, Takabe W, Jen N, et al. Ultrafine particles from diesel vehicle emissions at different driving cycles induce differential vascular pro-inflammatory responses: implication of chemical components and NF-kappaB signaling. Part Fibre Toxicol. 2010;7:6. Available from: http:// www.ncbi.nlm.nih.gov/pubmed/20307321

32. Shimada T. Xenobiotic-metabolizing enzymes involved in activation and detoxification of carcinogenic polycyclic aromatic hydrocarbons. Drug Metab Pharmacokinet. 2006;21:257-76. Available from: http://www.ncbi.nlm. nih.gov/pubmed/16946553

33. Jacob A, Hartz AM, Potin S, Coumoul X, Yousif S, Scherrmann J-M, et al. Aryl hydrocarbon receptor-dependent upregulation of Cyp1b1 by TCDD and diesel exhaust particles in rat brain microvessels. Fluids Barriers CNS. 2011;8: 23. [cited 2016 Jul 18]. Available from: http://www.ncbi.nlm.nih.gov/ pubmed/21867498 
34. Bonvallot V, Baeza-Squiban A, Baulig A, Brulant S, Boland S, Muzeau F, et al. Organic compounds from diesel exhaust particles elicit a proinflammatory response in human airway epithelial cells and induce cytochrome p450 1A1 expression. Am J Respir Cell Mol Biol. 2001;25:515-21. [cited 2016 Jul 13]. Available from: http://www.ncbi.nlm.nih.gov/pubmed/11694458

35. Totlandsdal Al, Låg M, Lilleaas $E_{,}$Cassee F, Schwarze P. Differential proinflammatory responses induced by diesel exhaust particles with contrasting PAH and metal content. Environ Toxicol. 2015;30:188-96. [cited 2016 Jul 13]. Available from: http://www.ncbi.nlm.nih.gov/pubmed/23900936

36. Kocbach A, Namork E, Schwarze PE. Pro-inflammatory potential of wood smoke and traffic-derived particles in a monocytic cell line. Toxicology. 2008;247:123-32. [cited 2015 Oct 13]. Available from: http://www. sciencedirect.com/science/article/pii/S0300483X08000851

37. Landskron G, De la Fuente M, Thuwajit P, Thuwajit C, Hermoso MA. Chronic inflammation and cytokines in the tumor microenvironment. J Immunol Res. 2014;2014:1-19. Available from: http://www.ncbi.n/m.nih.gov/pubmed/24901008

38. Park E-J, Park K. Induction of pro-inflammatory signals by 1-nitropyrene in cultured BEAS-2B cells. Toxicol Lett. 2009;184:126-33. Available from: http:// linkinghub.elsevier.com/retrieve/pii/S0378427408013295

39. Bhavaraju L, Shannahan J, William A, McCormick R, McGee J, Kodavanti U, et al. Diesel and biodiesel exhaust particle effects on rat alveolar macrophages with in vitro exposure. Chemosphere. 2014;104:126-33.

40. Saber AT, Jacobsen NR, Bornholdt J, Kjær SL, Dybdahl M, Risom L, et al. Cytokine expression in mice exposed to diesel exhaust particles by inhalation. Role of tumor necrosis factor. Part Fibre Toxicol. 2006;3:4.

41. Fujii T, Hayashi S, Hogg J, Mukae H, Suwa T, Goto Y, et al. Interaction of alveolar macrophages and airway epithelial cells following exposure to particulate matter produces mediators that stimulate the bone marrow. Am J Respir Cell Mol Biol. 2002;27:34-41.

42. Al-Sawaf O, Clarner T, Fragoulis A, Kan YW, Pufe T, Streetz K, et al. Nrf2 in health and disease: current and future clinical implications. Clin Sci (Lond). 2015;129:989-99. [cited 2016 Jul 4]. Available from: http://www.ncbi.nlm.nih. gov/pubmed/26386022

43. Sun H, Shamy M, Kluz T, Munoz AB, Zhong M, Laulicht F, et al. Gene expression profiling and pathway analysis of human bronchial epithelial cells exposed to airborne particulate matter collected from Saudi Arabia. Toxicol Appl Pharmacol. 2012;265:147-57.

44. Tsai M-J, Wang T-N, Lin Y-S, Kuo P-L, Hsu Y-L, Huang M-S. Aryl hydrocarbon receptor agonists upregulate VEGF secretion from bronchial epithelial cells. J Mol Med. 2015;93:1257-69.

45. Tsai MJ, Hsu YL, Wang TN, Wu LY, Lien CT, Hung CH, et al. Aryl hydrocarbon receptor (AhR) agonists increase airway epithelial matrix metalloproteinase activity. J Mol Med. 2014;92:615-28.

46. Koyama S, Sato E, Tsukadaira A, Haniuda M, Numanami H, Kurai M, et al. Vascular endothelial growth factor mRNA and protein expression in airway epithelial cell lines in vitro. Eur Respir J. 2002;20:1449-56.

47. Tseng C-Y, Wang J-S, Chao M-W. Causation by diesel exhaust particles of endothelial dysfunctions in cytotoxicity, pro-inflammation, permeability, and apoptosis induced by ROS generation. Cardiovasc Toxicol. 2016:1-9. Springer US. Available from: http://link.springer.com/10.1007/s12012-016-9364-0

48. Araujo JA, Barajas B, Kleinman M, Wang X, Bennett BJ, Gong KW, et al. Ambient particulate pollutants in the ultrafine range promote early atherosclerosis and systemic oxidative stress. Circ Res. 2008;102:589-96.

49. Bai N, Kido T, Suzuki H, Yang G, Kavanagh TJ, Kaufman JD, et al. Changes in atherosclerotic plaques induced by inhalation of diesel exhaust. Atherosclerosis 2011;216:299-306. Elsevier Ireland Ltd. Available from: https://doi.org/10.1016/j.atherosclerosis.2011.02.019.

50. Xu X, Kherada N, Hong X, Quan C, Zheng L, Wang A, et al. Diesel exhaust exposure induces angiogenesis. Toxicol Lett. 2009;191:57-68. Available from: http://www.ncbi.nlm.nih.gov/pubmed/19683567

51. Seilkop SK, Campen MJ, Lund AK, McDonald JD, Mauderly JL. Identification of chemical components of combustion emissions that affect proatherosclerotic vascular responses in mice. Inhal Toxicol. 2012;24:270-87. [cited 2016 Jul 19]. Available from: http://www.tandfonline.com/doi/full/10. 3109/08958378.2012.667455

52. Silverman DT, Samanic CM, Lubin JH, Blair AE, Stewart $P$ a, Vermeulen $R$, et al. The diesel exhaust in miners study: a nested case-control study of lung cancer and diesel exhaust. J Natl Cancer Inst. 2012;104:855-68.
53. Loomis D, Grosse Y, Lauby-Secretan B, El Ghissassi F, Bouvard V, BenbrahimTallaa $\mathrm{L}$, et al. The carcinogenicity of outdoor air pollution. Lancet Oncol. 2013;14:1262-3. Elsevier; [cited 2015 Apr 23]. Available from: http://www. thelancet.com/article/S147020451370487X/fulltext

54. Vermaelen K, Brusselle G. Exposing a deadly alliance: novel insights into the biological links between COPD and lung cancer. Pulm Pharmacol Ther. 2013;26:544-54. Elsevier Ltd

55. Wang $Y$, van Boxel-Dezaire AHH, Cheon H, Yang J, Stark GR. STAT3 activation in response to IL-6 is prolonged by the binding of IL-6 receptor to EGF receptor. Proc Natl Acad Sci U S A. 2013;110:16975-80.

56. Levy DE, Darnell JE Jr. Stats: transcriptional control and biological impact. Nat Rev Mol Cell Biol. 2002;3:651-62.

57. Huang $\mathrm{S}$. Regulation of metastases by signal transducer and activator of transcription 3 signaling pathway: clinical implications. Clin Cancer Res. 2007:13:1362-6.

58. Malanga D, De Marco C, Guerriero I, Colelli F, Rinaldo N, Scrima M, et al. The Akt1/IL-6/STAT3 pathway regulates growth of lung tumor initiating cells. Oncotarget. 2015;6:42667-86

59. Cao D, Bromberg PA, Samet JM. COX-2 expression induced by diesel particles involves chromatin modification and degradation of HDAC1. Am J Respir Cell Mol Biol. 2007;37:232-9.

60. Cartwright T, Perkins ND, L Wilson C. NFKB1: a suppressor of inflammation, ageing and cancer. FEBS J. 2016;283:1812-22. [cited 2016 Jul 1]. Available from: http://www.ncbi.nlm.nih.gov/pubmed/26663363

61. Li R, Mittelstein D, Kam W, Pakbin P, Du Y, Tintut $Y$, et al. Atmospheric ultrafine particles promote vascular calcification via the NF- B signaling pathway. AJP Cell Physiol. 2013;304:C362-9. [cited 2016 Jul 1]. Available from: http://www.ncbi.nlm.nih.gov/pubmed/23242187

62. Sunaga N, Kaira K, Imai H, Shimizu K, Nakano T, Shames DS, et al. Oncogenic KRAS-induced epiregulin overexpression contributes to aggressive phenotype and is a promising therapeutic target in non-small-cell lung cancer. Oncogene. 2013;32:4034-42. [cited 2016 Jul 14]. Available from: http://www.ncbi.n/m.nih.gov/pubmed/22964644

63. Longhin E, Capasso L, Battaglia C, Proverbio MC, Cosentino C, Cifola I, et al. Integrative transcriptomic and protein analysis of human bronchial BEAS-2B exposed to seasonal urban particulate matter. Environ Pollut. 2016;209:8798. [cited 2016 Apr 6]. Available from: http://www.ncbi.n/m.nih.gov/ pubmed/26647171

64. Riese D, Cullum R. Epiregulin: roles in normal physiology and cancer. Semin Cell Dev Biol. 2014;28:49-56. Available from: http://www.ncbi.nlm.nih.gov/ pubmed/24631357

65. Bach NS, Låg M, Øvrevik J. Toll like receptor-3 priming alters diesel exhaust particle-induced cytokine responses in human bronchial epithelial cells. Toxicol Lett. 2014;228:42-7. [cited 2017 Mar 28]. Available from: http://www. ncbi.n/m.nih.gov/pubmed/24709138

66. Van Den Heuvel R, Den Hond E, Govarts E, Colles A, Koppen G, Staelens J, et al. Identification of PM10 characteristics involved in cellular responses in human bronchial epithelial cells (Beas-2B). Environ Res. 2016;149:48-56. [cited 2017 Mar 28]. Available from: http://www. sciencedirect.com/science/article/pii/S0013935116301530

67. Kooter IM, Alblas MJ, Jedynska AD, Steenhof M, Houtzager MMG, van Ras M. Alveolar epithelial cells (A549) exposed at the air-liquid interface to diesel exhaust: first study in TNO's powertrain test center. Toxicol in Vitro 2013;27:2342-2349. Elsevier Ltd. Available from: https://doi.org/10. 1016/j.tiv.2013.10.007

68. Yu T, Zhang X, Zhong L, Cui Q, Hu X, Li B, et al. The use of a $0.20 \mu \mathrm{m}$ particulate matter filter decreases cytotoxicity in lung epithelial cells following air-liquid interface exposure to motorcycle exhaust. Environ Pollut. 2017:227:287-95. Elsevier Ltd. Available from: http://www.sciencedirect.com/ science/article/pii/S026974911632156X

69. Li N, Hao M, Phalen RF, Hinds WC, Nel AE. Particulate air pollutants and asthma. Clin Immunol. 2003;109:250-65. [cited 2017 Mar 28]. Available from: http://www.ncbi.nlm.nih.gov/pubmed/14697739 